\title{
Forced Equatorial Waves under the Marginally Stable State with Respect to Wave-CISK Mechanism
}

\author{
By Hisanori Itoh \\ Institute of Earth Sciences, Faculty of Education, Wakayama University, \\ Wakayama 640, Japan \\ (Manuscript received 22 October 1977, in revised form 24 March 1978)
}

\begin{abstract}
A theory for the excitation mechanism of stratospheric equatorial waves is proposed. The theory states that the tropical atmosphere is under the marginally stable state with respect to wave-CISK mechanism and that equatorial waves are forced ones under such circumstances.

It is shown from this theory that only the mode with the equivalent depth equal to that of the free wave in the marginal state or the slightly longer one is selectively excited, regardless of the profile of a forcing. Although the selected equivalent depth is shorter than the observed one when the Arakawa-Schubert's theory is used as the cumulus parameterization, the dominant periods in the stratosphere, at least, coincide with observed ones. Further considerations suggest that, under some devices of more complete parameterization, the longer equivalent depth seems to be selected. Then the dominant periods at the tropopause are close to those in the stratosphere, so that the vertical structure in the troposphere of the selected waves in the stratosphere may agree well with observations.

Assuming a lateral forcing as the excitation source of mixed Rossby-gravity waves and imposing the forcing in the form of a body forcing confined in mid-latitudes (not a boundary forcing), the selectivity for wavenumber is examined. With large meridional scale forcing, the waves with wavenumber 1 or 2 are not dominant and the waves of middle wavenumbers (3-7) are selected corresponding to those observed. Concerning the horizontal structure of the dominant waves, they also show a phase difference of about $90^{\circ}$ between meridional wind and geopotential in agreement with observations. It is difficult to specify the excitation source of Kelvin waves, but if thermal forcing is assumed to be the source at least, wavenumber 1 is selected.

Thus, this theory seems to explain well the characteristics of stratospheric equatorial waves, with a more complete parameterization of cumulus ensemble.
\end{abstract}

\section{Introduction}

The object of the present paper is to investigate the excitation mechanism for stratospheric equatorial waves. The previous work treating a thermal forcing by the present author (1977) has given such results that could explain the observed predominance of particular wavenumbers, but showed disagreement for the vertical wavelength and structure of the dominant waves. It was suggested that the vertical wavelength characteristic of equatorial waves never appeared without wave-cumulus interaction.

The selected vertical wavelength and structure may be corrected by introducing the interaction term into the vertical structure equation. Although the wave-CISK theory has shown that the waves interacting with cumulus convection are unstable for the CISK parameterization (e.g. Hayashi, 1970), this may probably be modified for another precise parameterization. If unstable waves may not be found in wave-CISK mechanism with a more complete parameterization, it becomes possible to interprete equatorial waves as forced ones interacting with cumulus activity. Then, both the selectivity of wavenumber and period and the vertical wavelength may agree with observations.

As to the cumulus parameterization, an epochmaking development was given by Arakawa and 
Schubert (1974). The re-examination of waveCISK theory using this parameterization was carried out by Stark (1976). According to his results, equatorial waves are not unstable when the autoconversion coefficient which represents conversion efficiency from liquid water in the cloud to precipitation has a realistic value. Therefore, if this parameterization is valid, it is concluded that equatorial waves interacting with cumulus are not self-exciting waves but forced ones. Moreover, from the result that the waves become unstable when the autoconversion coefficient has a slight larger value than a realistic one, the following important property may be ascertained. That is, the tropical atmosphere is under the marginally stable state with respect to the wave-CISK mechanism. When forcing is applied to such tropical atmosphere, the vertical wavelength of the selected equatorial waves is nearly equal to that of the free wave in the marginal state, irrespective of the vertical scale of the forcing. From this point of view, a new development in a forcing theory may be expected, which is investigated in Section 2.

Regarding forcing itself, there are many possible ways to excite equatorial waves in addition to thermal forcing. When we consider the selectivity for wavenumber, it is necessary to take a number of possible forcings into account. As a source exciting mixed Rossby-gravity waves, lateral forcing can be responsible, but Hayashi (1976) pointed out that previous lateral forcing theories (e.g. Mak, 1969) had weak points resulting from "boundary forcing". That is, wavenumber and period seem to be selected as the intersection in dispersion relations of two major free waves (the mixed Rossby-gravity wave and westward-moving "Kelvin wave") under a given vertical wavelength. When the given vertical wavelength is $10 \mathrm{~km}$, the selected wave has characteristics of wavenumber 4 and period of 4 days as observed. However, as westward-moving "Kelvin wave" which has not been observed in the real atmosphere has an essential effect, this is an fictitious selection. This invalid mode seems to appear from replacing a lateral forcing as a boundary forcing. Therefore, we must re-examine the selectivity for wavenumber and period after the correct boundary condition and the correct forcing are set up. In Section 3, we shall discuss this problem and see the wavenumber selection for mixed Rossby-gravity waves. In Section 4, the wavenumber selection for Kelvin waves will be considered.

\section{Forced equatorial waves interacting with cumulus convection}

\section{(1) Formulation}

In this section, we examine the nature of equatorial waves interacting with cumulus ensemble, using Arakawa-Schubert's parameterization (1974). For simplicity, the model used here is a normal mode one and we assume a thermal forcing as an excitation source of equatorial waves. The linearized version of cumulus parameterization is essentially identical to that of Stark (1976).

When we assume that perturbations are zonally propagating harmonic wave of wavenumber $k$ and frequency $\omega$, the linearized equations of zonal momentum, meridional momentum, hydrostatics and continuity without basic flow on equatorial beta-plane are written as follows:

$$
\begin{aligned}
& i \omega u^{\prime}-\beta y v^{\prime}=-i k \phi^{\prime}-d u^{\prime}, \\
& i \omega v^{\prime}+\beta y u^{\prime}=-\frac{\partial \phi^{\prime}}{\partial y}-d v^{\prime}, \\
& \frac{\partial \Phi^{\prime}}{\delta z}=\frac{R}{H} T^{\prime}, \\
& i k u^{\prime}+\frac{\partial v^{\prime}}{\partial y}+\frac{\partial w^{\prime}}{\partial z}-\frac{w^{\prime}}{H}=0,
\end{aligned}
$$

where the vertical coordinate is logarithmic pressure $\left(z=-H \ln \left(p / p_{o}\right)\right.$ and $\left.H=7 \mathrm{~km}\right)$. The notation is conventional ( $d$ represents Rayleigh friction and Newtonian cooling rates and is taken $1 / 30$ days) and the prime denotes the perturbation quantity. The thermodynamic equation including the effect of cumulus ensemble is

$$
i \omega s^{\prime}+w^{\prime} \frac{\overline{\partial s^{0}}}{\partial z}=Q c^{\prime}-d s^{\prime},
$$

where $s=c_{p} T+g z_{r}$ is static energy and $z_{r}$ is the real height (not "the height" by logarithmic pressure).

The interaction term $Q_{c}{ }^{\prime}$ is approximated as follows;

$$
Q_{c}^{\prime} \fallingdotseq \frac{M_{c}^{\prime}}{\rho^{0}} \frac{\partial s^{0}}{\partial z}-\frac{D^{\prime}}{\rho^{0}} L l^{0},
$$

where $M_{c}, D, l, \rho$ and $L$ are cumulus mass flux, detrained mass flux, liquid water in cloud, air density and the latent heat of condensation, respectively. A super-script 0 denotes a basic state variable. $l^{0}$ is determined in such a way as laterstated. In the right hand side in Eq. (6), the first term shows the adiabatic warming due to compensating downward motion around cumulus en- 
semble and the second term represents the effect where $X$ is the total mixing ratio and, therefore, of cooling due to the reevaporation of the de- $X-q_{c}$ corresponds to the cloud droplet and $\gamma=$ trained liquid water.

After the separation of variables, we have the vertical structure equation,

$$
\frac{d^{2} w}{d z^{2}}+\left(\frac{S R}{g h H}-\frac{1}{4 H^{2}}\right) w=\frac{R}{g h H} Q_{c},
$$

where $w^{\prime}=w(z) \phi(y) \mathrm{e}^{z / 2 H}$ and $Q_{c}{ }^{\prime}=Q_{c}(z) \phi(y) \mathrm{e}^{z / 2 H}$ and $h$ is a separation constant, generally known as an equivalent depth (see Stark, 1976). If $M_{c}{ }^{\prime}$ and $D^{\prime}$ can be uniquely represented by $w^{\prime}$, Eq. (7) can be solved, with use of Eq. (6).

For this purpose, we introduce the spectral expression of cloud mass flux following Arakawa and Schubert (1974) and use a finite difference model where any physical quantities are defined at same levels. In that case, the cloud mass flux and the detrained mass flux at a level $j$ are

$$
\begin{aligned}
& M_{c j^{\prime}}=\sum_{i=j+1}^{l \max } M_{b i}{ }^{\prime} \eta_{j i^{0}}+\frac{1}{2} M_{b j^{\prime}} \eta_{j j^{0}}, \\
& D_{j^{\prime}}=\frac{1}{\Delta z} \eta_{j j}{ }^{0} M_{b j^{\prime}} .
\end{aligned}
$$

Here $M_{b j}$ is the spectrum of cloud mass flux at the cloud base,

$$
\eta_{j l}= \begin{cases}\exp \left\{\lambda\left(z_{j}-z_{b}\right)\right\} & z_{b}<z<z_{l} \\ 0 & z>z_{l}\end{cases}
$$

is the normalized mass flux of type $\lambda$ cloud (or type $l$ cloud), $\lambda$ is the fractional entrainment rate of cloud which detrains at $z_{l}, l_{\max }$ denotes the tallest cloud type and subscript $b$ shows a variable at the cloud base. We define the moist static energy $h=s+L q$ and the saturation moist static energy $h^{*}=s+L q^{*}$ where $q$ denotes the mixing ratio of water vapor. Hereafter the asterisk represents the saturation value of the water vapor mixing ratio. Hence, $\eta_{j l}{ }^{0}$ and $l_{l}{ }^{0}$ are determined from the next relations.

$$
\begin{aligned}
& \eta_{j l^{0}} h_{c j l^{0}}=h_{b}{ }^{0}+\sum_{i=1}^{l} h_{i}^{0} \eta_{i l^{0}} \Delta z \\
& h_{c l l}{ }^{0} \fallingdotseq h_{l}{ }^{* 0} \\
& X_{j l^{0}}=\frac{1}{h_{j l^{0}}}\left[\eta_{j-1, l^{0}} X_{j-1, l}+q_{j}{ }^{0}\left(\eta_{j l^{0}}-\eta_{j-1, l^{0}}\right)\right] \\
& q_{c j l}{ }^{0} \fallingdotseq q_{j}{ }^{* 0}+\frac{1}{L} \frac{\gamma_{j}}{1+\gamma_{j}}\left(h_{c j l}{ }^{0}-h_{j}{ }^{* 0}\right) \\
& l_{j l^{0}}=\frac{X_{j l^{0}}-q_{c j l^{0}}}{1+K_{0} \Delta z / \eta_{j l^{0}}}
\end{aligned}
$$

and

$$
l_{l l}{ }^{0}=l_{l}^{0}
$$

$L / c_{p}\left(\partial q^{o *} / \partial T^{o}\right)_{p}$. Subscript $c$ represents the quantity in the cloud. $K_{O}$ is the autoconversion coefficient (see Stark, 1976) which is the only given parameter in this cumulus model. The total precipitation is expressed as follows:

$$
P^{\prime}=\sum_{l=2}^{l \max }\left(\sum_{j=2}^{l} P_{j l^{0}}\right) M_{b l^{\prime}}
$$

where

$$
P_{j l}{ }^{0}=K_{0} \Delta z l_{j l}{ }^{0}
$$

Hence, after all, $M_{b}{ }^{\prime}$ must be expressed by the terms of $w^{\prime}$.

The quasi-equilibrium assumption is used in order to obtain the relation between $M_{b}^{\prime}$ and $w^{\prime}$.

$$
\begin{aligned}
& \sum_{j=2}^{l-1} F_{j^{0}}\left(z_{j+(1 / 2)}-z_{j-(1 / 2)}\right)\left[\eta_{j l^{0}} i \omega\left(h_{c j l^{\prime}}-h_{j}{ }^{* \prime}\right)\right. \\
& \left.\quad+\frac{\partial \lambda_{l}}{\partial t}\left(z_{j}-z_{b}\right) \eta_{j l^{0}}\left(h_{c j l^{0}}-h_{j}^{* 0}\right)\right] \\
& \quad+F_{1}^{0}\left(z_{1(1 / 2)}-z_{b}\right) i \omega\left(h_{c 1 l^{\prime}}-h_{1}{ }^{* \prime}\right) \\
& \quad+F_{l}{ }^{0}\left(z_{l}-z_{l-(1 / 2)}\right)\left[\eta \eta l^{0} i \omega\left(h_{c l l^{\prime}}-h_{l}{ }^{* \prime}\right)\right. \\
& \left.\quad+\frac{\partial \lambda_{l}}{\partial t}\left(z_{l}-z_{b}\right) \eta_{l l l^{0}}\left(h_{c l l^{0}}-h_{l}{ }^{* 0}\right)\right] \fallingdotseq 0
\end{aligned}
$$

where $F_{j}{ }^{0} \equiv g / c_{q} T_{j}\left(1+\gamma_{j}\right) . \quad \partial \lambda_{l} / \partial t, h_{c j l^{\prime}}$ and $h_{j}{ }^{* \prime}$ fill the following relations:

$$
\begin{aligned}
& \eta_{j l^{0}} i \omega h_{c j l}{ }^{\prime}+\frac{\partial \lambda_{l}}{\partial t}\left(z_{j}-z_{b}\right) \eta_{j l^{0}} h_{c j l^{0}}=i \omega h_{b}{ }^{\prime} \\
& \quad+\sum_{i=2}^{j-1}\left[i \omega h_{i}\left(\eta_{i+1, l^{0}}-\eta_{i-1, l^{0}}\right)+\frac{\partial \lambda_{l}}{\partial t} h_{i^{0}}\right. \\
& \quad \times\left\{\left(z_{i+(1 / 2)}-z_{b}\right) \eta_{i_{+}(1 / 2), l^{0}}\right. \\
& \left.\left.\quad-\left(z_{i-(1 / 2)}-z_{b}\right) \eta_{i-(1 / 2), l^{0}}\right\}\right] \\
& h_{j}{ }^{\prime \prime}=\left(1+\gamma_{j}\right) s_{j}^{\prime} \text { and } h_{c l l^{\prime}}=h_{l}{ }^{\prime \prime} .
\end{aligned}
$$

As $s^{\prime}$ has the relation with $M_{b}^{\prime}$ and $w^{\prime}$ from Eq. (5), $h^{\prime}$ must be connected with $M_{b}^{\prime}$ and $w^{\prime}$. When we add Eq. (5) to the equation of water vapor budget

$$
L\left(i \omega q^{\prime}+w^{\prime} \frac{\partial q^{0}}{\partial z}\right)=Q_{m^{\prime}},
$$

where

$$
Q_{m^{\prime}}=\frac{M_{c}^{\prime} L}{\rho^{0}} \frac{\partial q^{0}}{\partial z}+\frac{D^{\prime} L}{\rho^{0}}\left(q^{* 0}-q^{0}+l^{0}\right),
$$

we obtain the equation of moist static energy; 


$$
i \omega h_{j}{ }^{\prime} \fallingdotseq \frac{M_{c}^{\prime}}{\rho^{0}} \frac{\partial h^{0}}{\partial z}-w^{\prime} \frac{\partial h^{0}}{\partial z}+\frac{D^{\prime} L}{\rho^{0}}\left(q^{* 0}-q^{0}\right)
$$

Thus, the right hand side is represented by the relation between $M_{b}{ }^{\prime}$ and $w^{\prime}$. By substituting Eqs. (5) and (15) into Eq. (12), the relation between $M_{b}{ }^{\prime}$ and $w^{\prime}$ is obtained in symbolic expression of matrix form as follows:

$$
\left[M_{b}{ }^{\prime}\right]=\left[B_{i j}\right]\left[w^{\prime}\right]
$$

Using Eq. (6), the net heating function is

$$
\left[Q_{c}^{\prime}\right]=\left[C_{i j}\right]\left[w^{\prime}\right] \text {. }
$$

Hence,

$$
\left.\left[Q_{c}\right]=\left[C_{i j} e^{\left(\left(z_{j}-z\right)\right.}{ }_{i} / 2 H\right)\right][w]=\left[A_{i j}\right][w],
$$

where $A_{i j}=C_{i j} \exp \left\{\left(z_{j}-z_{i}\right) / 2 H\right\}$.

Therefore, the vertical structure equation at a level $i$ is, adding a external forcing,

$$
\begin{aligned}
& \frac{d^{2} w_{i}}{d z^{2}}+\left(\frac{S_{i} R}{g h H}-\frac{1}{4 H^{2}}\right) w_{i} \\
& =\frac{\kappa}{g h H}\left(Q_{i}+\sum_{j} A_{i j} w_{j}\right) \text { for } 0<z_{i}<z_{l \max },
\end{aligned}
$$

$$
\frac{d^{2} w_{i}}{d z^{2}}+\left(\frac{S_{i} R}{g h H}-\frac{1}{4 H^{2}}\right) w_{i}=0 \text { for } z_{i}>z_{\max } .
$$

The lower boundary condition is

$$
w=0 \text { at } z=0 \text {, }
$$

and the upper boundary condition is the radiation condition.

The temperature and moisture fields of the basic state in this model are shown in Fig. 1, which are based on the soundings in the hurricane season of Jordan (1956). We take $500 \mathrm{~m}$ as the grid interval in vertical direction as we need the fine resolution to some extent and the cloud base is set at $500 \mathrm{~m}$. Moreover, $h^{0}$ at the cloud base $\left(h_{b}{ }^{0}\right)$ is assumed to be the same value as that at the surface. Then $z_{l \max }$ is found to be $14.5 \mathrm{~km}$ (hereafter denoted as $z_{t}$ instead of $z_{\text {lmax }}$ ).

We thus calculate $A_{i j}$ and find that, among elements of matrix $A$, diagonal elements and those concerned with $w$ at the cloud base $\left(w_{b}\right)$ have fairly larger values than other elements.

The external heating is taken as follows;

$$
Q_{i}= \begin{cases}Q_{0} \sin \pi\left(z_{i} / z_{t}\right) & \text { for } 0<z_{i}<z_{t} \\ 0 & \text { for } z_{i}>z_{t} .\end{cases}
$$

It will be shown that the vertical wavelength of dominant waves does not depend on the shape

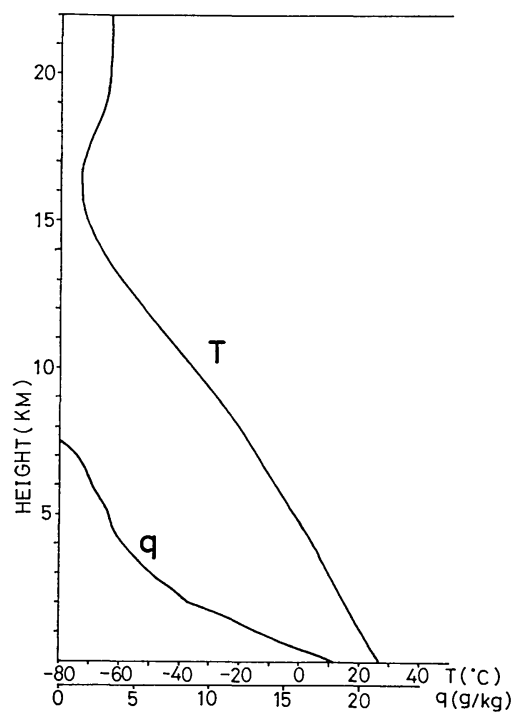

Fig. 1 Zonal mean temperature and mixing ratio with height used in this model, adopted from the soundings in the hurricane season of Jordan (1956).

of a forcing. $Q_{0}$ is not a constant with respect to wavenumber and period but is defined in a similar way to that in subsection 2-3 of Itoh (1977). However, there are no essential differences from the case of constant $Q_{0}$, because the selectivity of the particular mode is marked.

(2) Results

First, we examine the stability property of equatorial waves interacting with cumulus, putting $Q_{i}=0$ in Eq. (18). When we give an autoconversion coefficient, $K_{o}, 2 \mathrm{~km}^{-1}$ which is a realistic value, the waves are stable, while in the case of $K_{o}=5 \mathrm{~km}^{-1}$ they become unstable with $h=6.43\left(\equiv h_{c}\right)+0.22 i$ (meters). Thus, the tropical atmosphere is under the marginally stable state with respect to wave-CISK in this model. Therefore, it is considered that the tropical atmosphere excites the mode only with $h \sim h_{c}$ selectively, when a forcing is given to such circumstances.

Fig. 2 shows the zonal wind amplitude of Kelvin waves (wavenumber 1 and 2 , hereafter denoted as $s=1$ and 2) and Fig. 3 illustrates the meridional wind amplitude of mixed Rossbygravity waves $(s=4)$, with precipitation amplitude, as a function of period and height. In general, it is found that the modes of $h=h_{c}$ (periods of 58 days, 29 days and 6.5 days for Kelvin waves of $s=1$ and 2 and for mixed Ross- 

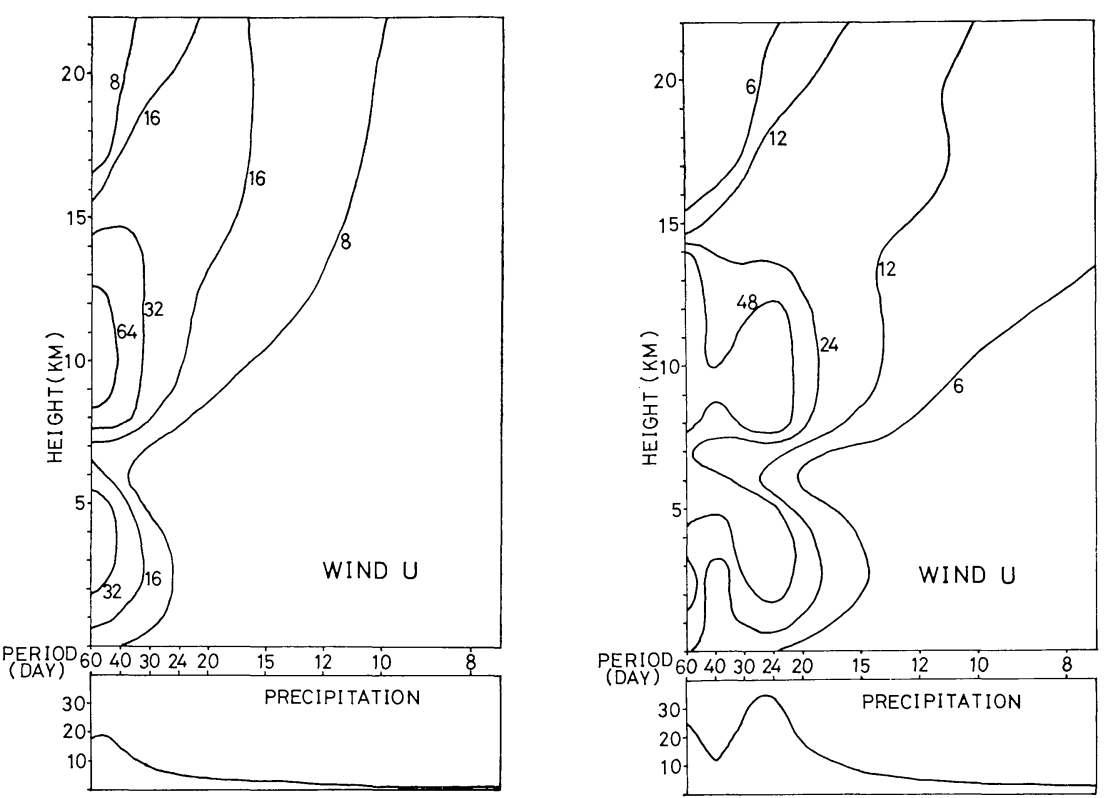

Fig. 2 Perturbation zonal wind $(\mathrm{m} / \mathrm{sec}$.) over the equator, with precipitation amplitude $\left(\mathrm{kg} / \mathrm{m}^{2} /\right.$ day), of Kelvin waves with (a) $s=1$ and (b) $s=2$ as a function of period and height.

by-gravity waves of $s=4$, respectively) are remarkably excited as a result of the interaction with cumulus, in contrast to the result from thermal forcing only, which have the maximum response at 10 days, 5 days and 3.3 days (not shown), respectively. In more detail, the mode with $h \sim h_{c}$ in precipitation and the mode with slightly larger equivalent depth $\left(\equiv h_{w}\right)$ i.e. shorter periods in wind have the maximum amplitude. The dominant periods in the stratosphere are shorter than that near the tropopause. Therefore, it is concluded that the dominant waves are not dependent on the structure of a forcing and that the mode with $h \sim h_{w}$ is selected even if the amplitude of a forcing with any wavenumbers and periods except those corresponding to $h \sim h_{w}$ is considerably large. As a whole, it is the defect that $h_{c}$ (and $h_{w}$ ) is too short, but it seems to be modified longer for a more realistic parameterization as will be discussed in Section 5, as it is essentially dependent on the cumulus parameterization.

Let us consider the selectivity for Kelvin wave. It may be forgiven to neglect the waves of $s=3$ or more as the response amplitude is small even under the assumption of white noise forcing. As shown in Fig. 2, near the tropopause intense peaks are seen at periods of 30-40 days for $s=1$ and period of 20 days for $s=2$. In the strato- sphere the waves show the peak at period of about 20 days with $s=1$. Therefore, when we follow the peak near 20 days period in vertical direction, wavenumber 2 takes charge of the peak near the tropopause and wavenumber 1 is more dominant with increasing height. The peak at long periods at the tropopause is seen in the analysis of Parker (1973) and the other features are similar to the results from Wallace and Kousky (1968) and Kousky and Wallace (1971) except that dominant periods are slightly longer as a result of the above-mentioned defect of $h_{c}$. Moreover, the peak near 12 days in the stratosphere for $s=2$ coincides with Odo (1976) and others. Although we cannot explain well the analysis of Parker (1973) that the peak at periods of 30-40 days can be seen only at times, it may be connected with the shear of mean zonal wind in the troposphere, as even the weak shear gives large influences for the mode with short equivalent depth.

Regarding mixed Rossby-gravity wave, the peaks at 6 days near the tropopause and at 44.5 days in the stratosphere are found. These show the characteristics of observations (Yanai and Murakami, 1971 and others) except that the peak period near the tropopause is slightly longer. The waves of other wavenumbers also give the similar feature. 
It is interesting to compare these results with the analyses of the general circulation model (GCM). Hayashi (1974) and Tsay (1974) analysed equatorial waves from the GFDL and NCAR GCMs' products, respectively. Although these models adopt the convective adjustment as the cumulus parameterization, equatorial waves may be considered to be formed by the same mechanism, as the nature of waves is well simulated. However, the selectivity of equivalent depth must depend on this parameterization. The selected equivalent depth (corresponding not to $h_{c}$ but to $h_{w}$ ) estimated from the results of Tsay (1974) (as the shear of mean zonal wind is weak) considering the westerly flow in the troposphere is about $25-30 \mathrm{~m}$, which is longer than the result here and seems to be shorter than the observed one. The peak for Kelvin waves of $s=1$ is seen at 15 days in Hayashi (1974) and it does not seem to be consistent with the analysis of Tsay (1974). However, it may be interpreted as that the waves with long periods are absorbed for the strong easterly in the stratosphere and, in consequence, the waves with period of 15 days can be observed. Actually the feature that peaks of power spectra shift from longer periods to shorter ones with increasing height is shown in Fig. 8(a) of Hayashi (1974).

Spectral analyses for precipitation in "observations" show that eastward-moving modes have the red noise spectra so that they have no peak corresponding to the wind peak of Kelvin waves while westward-moving modes have a weak peak near the peak period in wind power of mixed Rossby-gravity waves (Gruber, 1974; Hayashi, 1974). This model may explain these characteristics as follows. Fig. 2 shows that the spectra in precipitation of wavenumber 2 and 1 of Kelvin waves have the maxima at about 26 days and 50 days, respectively. The peaks are relatively dull for the influence of the dissipation. Hereupon, if the mean zonal flow in the troposphere is the strong easterly (or has the strong shear), the precipitation has no spectral peak and is characterized by the spectral distribution of red noise type.* With mixed Rossby-gravity wave, the peak of precipitation appears at the period somewhat longer than the peak period of wind power in the stratosphere (Fig. 3) in accordance with observations. Although the spectral peak of precipitation is not so strong in the "real"

* We conjecture that the cause of it is the same as that wind peaks with period of 30-40 days at the tropopause can be seen only at times.

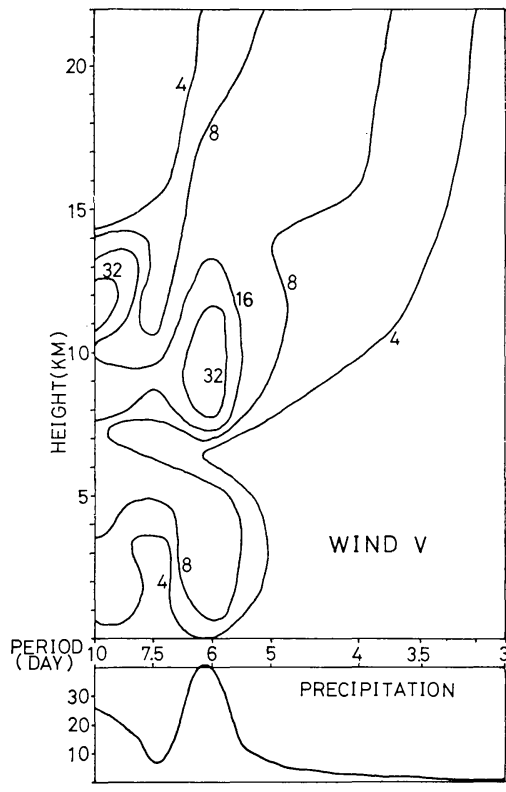

Fig. 3 Perturbation meridional wind $(\mathrm{m} / \mathrm{sec})$ over the equator, with precipitation amplitude $\quad\left(\mathrm{kg} / \mathrm{m}^{2} /\right.$ day $)$, of mixed Rossby-gravity waves with $s=4$ as a function of period and height.

atmosphere, distinct peaks are seen here. This difference, however, may be considered to arise from the means of spectral analysis for precipitation with non-normal distribution (Wallace, 1971 $564 \mathrm{p})$. For a physical quantity such as precipitation, it is easily imagined that the spectra show the false peak at the period of one-half the original one and that the power of the original period becomes weak. When we look at the power spectra of precipitation in Hayashi (1974) in such viewpoint, it is interesting that the peak is found out at about 2.5 days.

Next, let us examine the vertical structure of dominant waves at the tropopause. Fig. 4 shows the vertical structure of Kelvin wave with $s=2$ and period of 24 days and Fig. 5 illustrates that of mixed Rossby-gravity wave with $s=4$ and period of 6.00 days. The heating and the upward motion have the in-phase relation. The wind component tilts in the direction opposite to the propagation one with height in the lower layer and in the same direction in the upper layer. These features agree well with observations. Concerning the temperature, the inclination opposite to observations is seen at about $4-5 \mathrm{~km}$ and 


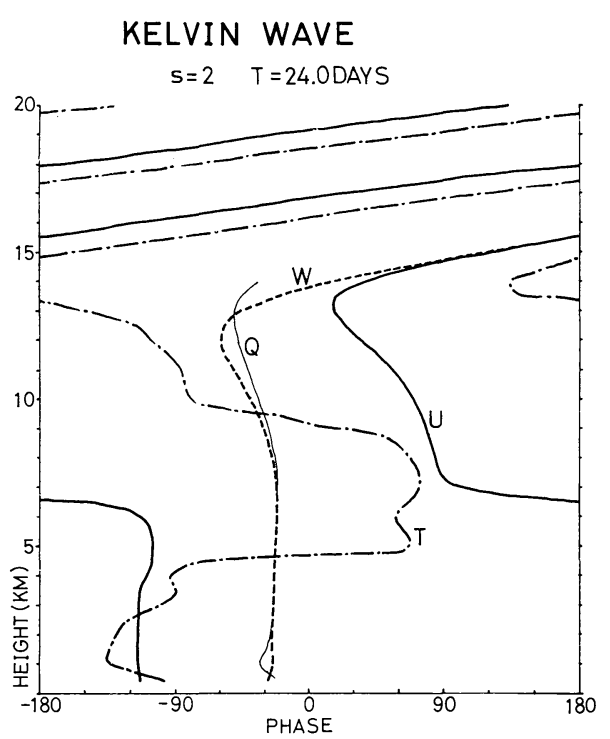

Fig. 4 Vertical profile of phase angle of $w^{\prime}, u^{\prime}, T^{\prime}$ and $Q^{\prime}$ for Kelvin wave with $s=2$ and period of 24 days. $Q^{\prime}$ is the composite heating of the external heating and the cumulus heating interacting with waves. The cumulus heating is overwhelmingly larger than the external heating near the dominant period.

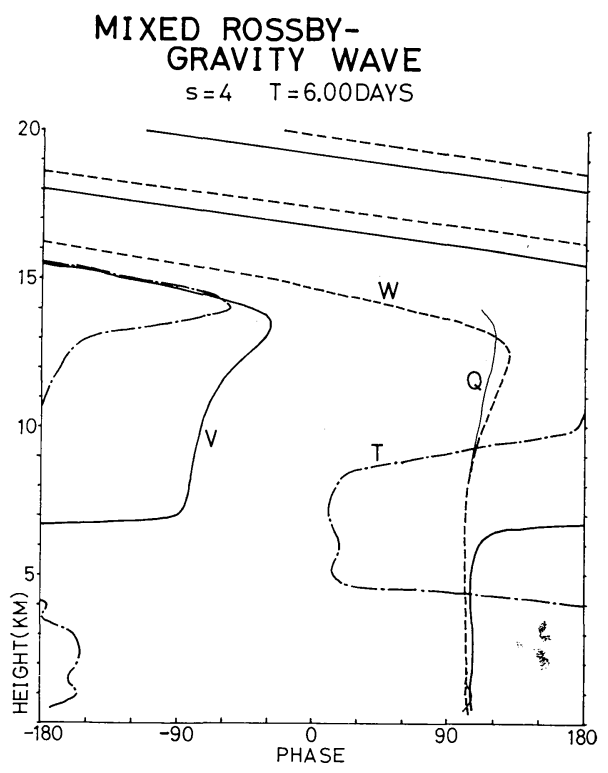

Fig. 5 Vertical profile of phase angle of $w^{\prime}, v^{\prime}, T^{\prime}$ and $Q^{\prime}$ for mixed Rossby-gravity wave with $s=4$ and period of 6.00 days.
$13 \mathrm{~km}$ heights, but this difference is not essential because it has only small amplitude at these levels. The vertical wavelength in the stratosphere does not coincide as a matter of course. Moreover, the dominant waves in the stratosphere show a different feature from the observed waves in the vertical structure in the troposphere (not shown). Those are also caused by that $h_{c}\left(h_{w}\right)$ is too short. If it becomes longer by an improvement of the cumulus parameterization, the prominent waves in the stratosphere in this theory may agree with observations even in those points, as the dominant period in the stratosphere becomes close to that near the tropopause.

Thus, it is proved that the present model explains the many characteristics of the observed waves under a given wavenumber. However, the discussion so far has been restricted to thermal forcing only as the forcing to excite equatorial waves. Other possible forcings exist actually. Taking these sources into account, it is necessary to consider the selectivity for wavenumber further.

\section{Wavenumber selection for mixed Rossby- gravity wave}

As forcing to excite mixed Rossby-gravity waves, there can be lateral forcing in addition to thermal forcing. In the present theory we consider that the observed cumulus heating is the enhanced one by the interaction with large-scale waves which are originally forced. Thus thermal forcing defined here is an original heating which is formed without the relation to waves. A wavenumber and period of large-scale thermal forcing result from a statistical property of random and local cumulus heatings, so it is conjectured that thermal forcing does not have large amplitude. The object of this section is to examine the wavenumber selection for the waves excited by lateral forcing.

What is the correct treatment for the problem of excitation by lateral forcing? The primary fault in previous models is that westward-moving "Kelvin waves" which have not been found in the real atmosphere appear. This arises from the fictitious assumption that the waves in the models have non-zero amplitude at the boundary, because waves in the actual atmosphere move under the constraint that they cannot have their amplitude at the pole. From this discussion, we here use the model including the pole and put the perturbed geopotential with zero amplitude there. Moreover, the forcing is set all over the mid- 
latitudes (body forcing). The second reconsideration should be made concerning the normalization of the physical quantity. By normalizing the wave amplitude (meridional wind) or the transport of energy at the boundary and comparing the wave amplitude over the equator, the selectivity has been examined. However, westwardmoving waves in mid-latitudes excited by a forcing must have different amplitude by wavenumber and period by the difference of the response property. Therefore, it is appropriate to normalize a forcing and to see the dominance of waves over the equator which is the results of the response of mid-latitude waves to the forcing and the propagation of the waves to the equator, rather than previous methods.

In order to see the selectivity for wavenumber and period, it convinces us best to examine the dominance of the meridional wind amplitude over the equator on the full wavenumber-period section, using the model including the wave-cumulus interaction. However, it is impractical because of much calculation time consuming. As the wave-cumulus interaction excites the mode only with $h \sim h_{w}$ selectively, it may sufficiently be substituted by the discussion only for the waves with pairs of wavenumber and period which fill the dispersion relation of $h \sim h_{w}$ for mixed Rossbygravity wave. Moreover, it is not necessary to include the wave-cumulus interaction in the model, because it has only the effect to strengthen the wave amplitude in the tropical area at the same rate under the same equivalent depth. Therefore, we use the same model as Eq. (51) in the previous work (Itoh, 1977) except the treatment of thermal forcing. However, it should be noted that the vertical motion, the convective heating and the precipitation become large at the different rate by the different period even under the same equivalent depth. That is, they are proportional to the frequency.

Next, let us give a mid-latitude forcing with a mid-latitude heating $Q$. Even if there are actually forcings by the non-linear interaction of waves and so on, these effects are included in the heating term in this model and it is generalized by calculating the response to various modes of "mid-latitude heating". It is easily shown that barotropic modes dominate within the range of wavenumbers and periods corresponding to $h \sim h_{w}$ and that the wave amplitude is insensitive to the vertical profile of $Q$. In order to calculate the response to various latitudinal modes of $Q$, we set the mid-latitude heating as follows:

$$
Q=\left\{\begin{array}{c}
Q_{1} \sin \left\{\left((1-y) /\left(1-y_{0}\right) m \pi\right\} \sin \left\{\left(2 \pi / z_{t}\right) z\right\}\right. \\
y_{0}<|y|<1 \text { and } 0<z<z_{t}, \\
0 \quad|y|<y_{0} \text { or } z>z_{t},
\end{array}\right.
$$

where $Q_{1}=1{ }^{\circ} \mathrm{K} /$ day, $y_{0}=6 / 13$ (about $27.5^{\circ}$ ) and we choose $m=1,2$ and 3 . We take the case of $h=20$ and 50 meters.

Fig. 6 shows the meridional wind amplitude of westward-moving antisymmetric modes at $5 \mathrm{~km}$ over the equator obtained in this model as a function of wavenumber (period). Similar features are found for the amplitude at other heights. It is seen from this figure that middle wavenumbers are selected for low latitudinal modes of $Q$. In the real atmosphere the forcing with large meridional scale is considered to be dominant. The wave amplitudes of $s=1$ and 2 are considerably small in many cases. Therefore, even under the real forcing which is considered to have the maximum at wavenumber 1 or 2 , middle wavenumbers are also selected in agreement with observations.

The horizontal structure of westward-moving antisymmetric mode with $s=4$ and 4.39 day period for $m=1$ forcing is shown in Fig. 7, from which this wave is identified with mixed Rossbygravity wave. The phase relation between $\phi^{\prime}$ and

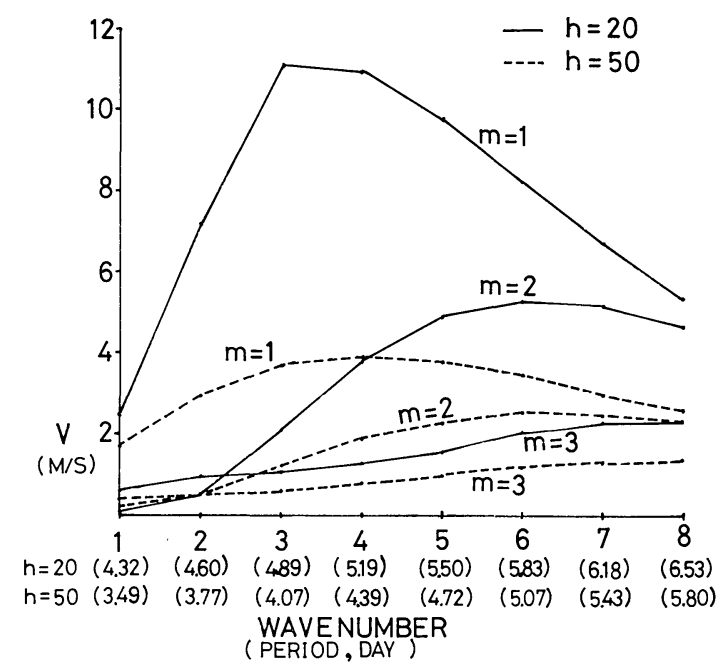

Fig. 6 Perturbation meridional wind $(\mathrm{m} / \mathrm{sec})$ at $5 \mathrm{~km}$ over the equator to various latitudinal modes of lateral forcing as a function of wavenumber (period). The cases of 20 and 50 meters as the equivalent depth and $m=1,2$ and 3 as the latitudinal mode of forcing are shown. 


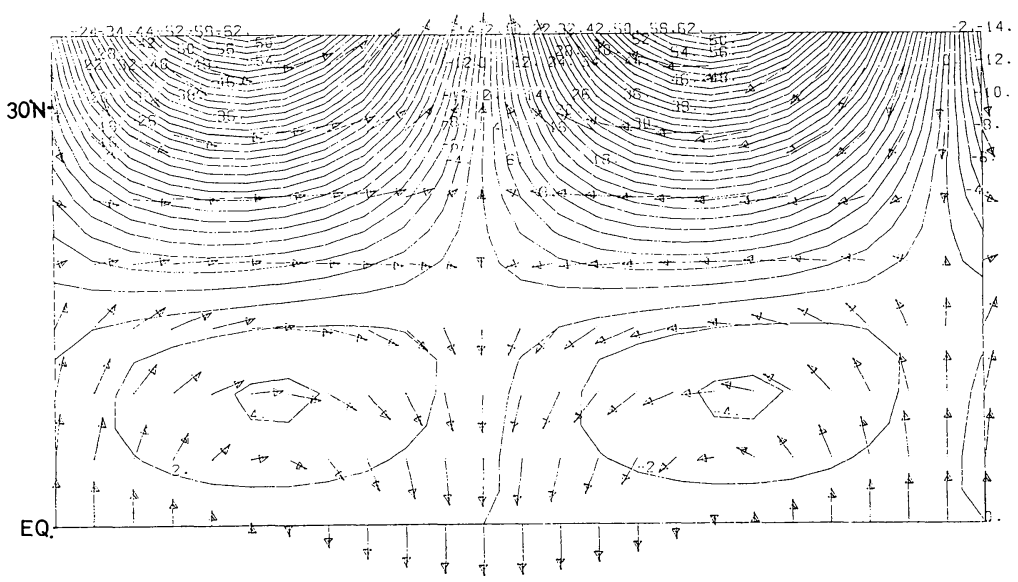

Fig. 7 Horizontal structure of geopotential (solid line) and wind (arrow) at $5 \mathrm{~km}$ for westward-moving antisymmetric mode of wavenumber 4 and period of 4.39 days.

$v^{\prime}$ is in quadrature and westward-moving Kelvin waves do not appear.

If the cumulus parameterization is included in this model, the wave amplitude may become large only in the tropical area (because the marginally stable state is realized only there) and remarkably exceed that in mid-latitudes, for such pairs of wavenumber and period. Therefore, in midlatitudes it may not be necessary that the amplitude of westward-moving waves with $s=4$ and period of 4-5 days is large enough to be observed for spectral analyses. Instead, spectral peaks, except those corresponding to baroclinic unstable waves and stationary ones, will be seen at (barotropic) resonant periods and wavenumbers (e.g. Deland, 1973) which are not connected with wave-cumulus interaction. The horizontal structure will also be similar to Fig. 7, as the effect of interaction with cumulus convection strengthens the wave amplitude, changes the vertical phase relation but does not influence the horizontal phase relation.

\section{Wavenumber selection for Kelvin wave}

As sources exciting Kelvin waves, there are monsoon disturbances (thermal forcing in the subtropics) proposed by T. Murakami (1972), in addition to thermal forcing in the tropics and lateral forcing. However, many questions arise as to which forcing is essentially effective. Concerning lateral forcing, there is a problem that Kelvin waves are eastward-moving waves so that they necessarily have a critical latitude between the mid-latitude westerlies and the tropical easterlies. According to a linear theory the wave energy is absorped there, but, in a non-linear theory including wave-zonal flow interaction, whether it is absorped there or can propagate to the equator-side is yet controversial problem (Geisler and Dickinson, 1974; M. Murakami, 1974; Beland, 1976 and others). If the monsoon disturbances are the excitation source, the seasonal variation of the power of Kelvin waves must be observed. (Properly, wave amplitude depends on not only the forcing amplitude but also the closeness to the marginal state of the tropical atmosphere, in the present model.) However, such a study has not been achieved.* Thus, as there are many open questions, the overall investigation to the wavenumber selection for Kelvin wave must be reserved.

Saying just a word, if thermal forcing is the main excitation source, wavenumber 1 is selected as observed even under the white noise forcing. Moreover, as it is considered that, in forcings themselves, small wavenumbers such as wavenumber 1 or 2 are dominant, the selectivity of wavenumber 1 will be very sharp.

\section{On properties of equatorial waves for a more complete parameterization of cumulus}

In Section 2, the vertical wavelength of dominant waves was shown to be too short. However, this is essentially dependent on the cumulus

* Recently, such a study was made by Hayashi (1977) for Kelvin waves appearing in GFDL GCM. According to him, the spectral power of Kelvin waves of wavenumber 1 with 15 days period is very marked in the monsoon season. 
parameterization term of the vertical structure equation. Very recently, some methods to improve the expression of the cumulus property have been proposed. Nitta (1977) included the effect of the moist downdraft in spectral expression of cumulus and analysed the properties of cumulus in the GATE data. According to him, the total cloud mass flux diminishes and the deep cloud mass flux increases and the shallow cloud mass flux decreases due to this effect. Yamazaki (1977) proposed to consider the critical liquid water content in clouds and the ice phase. The former effect mainly diminishes the total precipitation, and the latter one increases the taller cloud mass flux and decreases the shorter cloud mass flux. Both methods diminish the total cloud mass flux, and emphasize the deep cloud and reduce the shallow cloud (although we cannot know directly how distribute the spectra of cloud when the moist downdraft is included in a theoretical model, as Nitta's model is not a model for theory but for analysis). These are the improvement for that Arakawa-Schubert's theory has generally been said to overestimate the shallow cloud. To be interesting to us is how influences these improvements give on the selection of the vertical wavelength and the vertical structure.

First, for simplicity let us change the matrix showing the relation between $M_{b}^{\prime}$ and $w^{\prime}$ (Eq. 16 , hereafter referred to as matrix $B$ ) arbitrarily, and see the vertical wavelength and the vertical structure of the selected waves by the same model as in Section 2. This is also a test of sensitivity for the marginally stable state with respect to wave-CISK mechanism. As both the abovementioned improvements reduce the total cloud mass flux and increase (decrease) the deep (shallow) cloud mass flux, we change the matrix $B$ as follows; all matrix elements are multiplied by $a$, the uppermost line (which expresses $M_{b 1}$ ) by $b$, the lowest line (which expresses $M_{b l \max }$ ) by $c$ and the other lines are multiplied by the value interpolated linearly between $b$ and $c$. That is,

$$
\left(\begin{array}{c}
M_{b 1} \\
\vdots \\
\vdots \\
\vdots \\
M_{b l \max }
\end{array}\right)=a\left(\begin{array}{c}
-\times b \\
\vdots \\
\vdots \\
\vdots \\
\mathbf{B}_{l j}
\end{array}\right)\left(\begin{array}{c}
w_{1} \\
\vdots \\
\vdots \\
\vdots \\
w_{l \max }
\end{array}\right)
$$

Table 1 shows the results to changes of matrix $B$. Apparently the equivalent depth becomes longer when the total cloud mass flux decreases. As the autoconversion coefficient forming un-
Table 1. Equivalent depth in the marginal state and autoconversion coefficient which makes the marginal state, to the modified matrix $B$. Autoconversion coefficients were increased by $1 / \mathrm{km}$ till the unstable waves were formed.

\begin{tabular}{llcc}
\hline & & $\begin{array}{c}\text { equivalent } \\
\text { depth } \\
\text { (meters) }\end{array}$ & $\begin{array}{c}\text { autocoversion } \\
\text { coefflcient } \\
\text { (km) }\end{array}$ \\
\hline original & $\begin{array}{l}a=1, b=1, \\
c=1\end{array}$ & 6.43 & 5 \\
case I & $\begin{array}{l}a=1, b=0.8, \\
c=1.2 \\
\text { case II }\end{array}$ & $\begin{array}{l}a=0.9, b=0.8, \\
c=1.2\end{array}$ & 10.16 \\
\hline
\end{tabular}

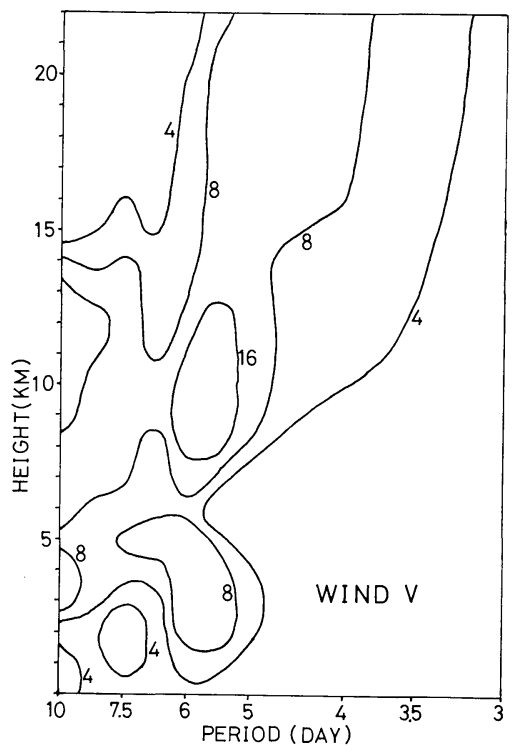

Fig. 8 Perturbation meridional wind $(\mathrm{m} / \mathrm{sec}$.) over the equator of mixed Rossbygravity waves with $s=4$ to case II.

stable waves is considerably large in case II, the marginally stable state with respect to waveCISK mechanism seems to be broken. However, the waves with $h \sim h_{c}$ (5.92 day period) and slightly larger equivalent depth have fairly large amplitude, as seen in Fig. 8 which shows wave amplitude for forced mixed Rossby-gravity waves of $s=4$ when $K o=2 / \mathrm{km}$ in case II. Therefore, we can safely say that dominant waves are formed by the marginally stable state with respect to wave-CISK mechanism even for such spectral distribution of clouds. The wave with period of 5.45 days has the maximum amplitude near the tropopause, and the wave with 4.29 day period is selected in the stratosphere, 
which has the same period as the wave in the original case (Fig. 3), regardless of the difference of the selected equivalent depth. The vertical structure in the troposphere of the wave with period of 5.45 days also coincides with the observed one (not shown). However, that of the dominant wave in the stratosphere does not agree as before.

For a more general development in cumulus parameterization, we consider the vertical structure and the vertical wavelength (equivalent depth) of dominant waves. Regarding the vertical structure, it may be shown to coincide with the observed one irrespective of cumulus parameterization. For example, let us examine about Kelvin wave for simplicity. The axis of $w^{\prime}$ will stand straightly in vertical in phase of $Q_{c}{ }^{\prime}$ for any parameterization. The wind converges toward the axis of $w^{\prime}$ in the lower troposphere and, on the other hand, diverges from it in the upper troposphere. Therefore, $u^{\prime}\left(\phi^{\prime}\right)$ is in quadrature with $w^{\prime}$ at lower and upper troposphere, and $u^{\prime}\left(\phi^{\prime}\right)$ itself is out of phase between lower and upper troposphere. The wave in these situations forms such structure as either of Fig. 9(a) or (b). As the energy flux $\overline{\phi^{\prime} w^{\prime}}$ must be downward for the vertical motion at the cloud base to become large in the marginally stable state, the structure such as Fig. 9(a) will be realized, which agrees with the observed structure.

The selectivity for the vertical wavelength essentially depends on the matrix $A$ (Eq. 17). As mentioned in Section 2, this matrix has large values at the first row and diagonal elements. Therefore, we assume following equations by replacing Eqs. (18) and (19);

$$
\frac{d^{2} w}{d z^{2}}+\lambda_{1}{ }^{2} w=\frac{\kappa}{h H} f \sin \frac{\pi}{z_{t}} z \cdot w_{b} \quad 0<z<z_{t},
$$

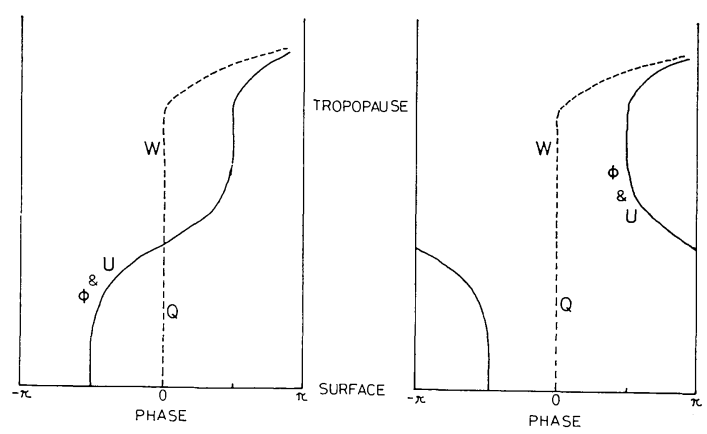

Fig. 9 Schematic figures of the possible vertical profiles for phase angles of $\phi^{\prime}\left(u^{\prime}\right)$ and $w^{\prime}\left(Q^{\prime}\right)$.

$$
\frac{d^{2} w}{d z^{2}}+\lambda_{2}^{2} w=0 \quad z>z_{t},
$$

where

$$
\lambda_{1}{ }^{2}=\frac{\kappa}{h H} \frac{1}{\alpha}-\frac{1}{4 H^{2}}-\frac{\kappa e}{g h H}
$$

and

$$
\lambda_{2}{ }^{2}=\frac{\kappa}{h H}-\frac{1}{4 H^{2}} .
$$

This is identical to assume the matrix $A$ such as

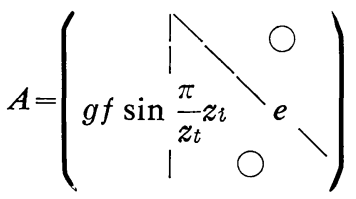

The stratosphere is assumed to be isothermal and $\alpha$ is the ratio of the static stability in the stratosphere to that in the troposphere. This equation is the same as the wave-CISK equation under a CISK parameterization except subtracted a factor $\kappa e / g h H$ in $\lambda_{1}{ }^{2}$ in Eq. (20). In this case, the equivalent depth of the wave in the marginal state is, as shown in Appendix,

$$
h \fallingdotseq \frac{\kappa}{H} \frac{z^{2}}{4 \pi^{2}}\left(\frac{1}{\alpha}-\frac{e}{g}\right)
$$

which is fairly shorter than that in the CISK parameterization $\left(h_{u} \fallingdotseq(\kappa / H \alpha)\left(z_{t}{ }^{2} / 4 \pi^{2}\right)\right)$. Solution (22) apparently shows that, the smaller become diagonal elements in the matrix $A$, the longer becomes the selected equivalent depth, setting $h_{u}$ as the upper limit. The reason why the equivalent depth lengthens in the case II is because diagonal elements in the matrix $A$ reduce with decreasing the total cloud mass flux.

From above discussions, even if $a$ more general development in cumulus parameterization is achieved, following conclusions obtained in this theory will still hold:

1) Equatorial waves are selected from that the tropical atmosphere is under the marginally stable state with respect to wave-CISK mechanism.

2) The periods selected in the stratosphere are about 4.3 days for mixed Rossby-gravity wave of $s=4$ and about 18 days for Kelvin wave of $s=1$.

3) The vertical structure in the troposphere of the dominant waves near the tropopause coincides with the observed one.

On the other hand, following contents may be changed for a more precise parameterization;

1) the selection of the equivalent depth and 
the vertical wavelength for the dominant waves near the tropopause,

2) the vertical structure in the troposphere of the prominent waves in the stratosphere.

If the equivalent depth of the wave in the marginal state lengthens and becomes close to that of the dominant waves in the stratosphere by the development of cumulus parameterization, this theory is considered to almost satisfy the matters which must be explained in the model of the excitation mechanism for stratospheric equatorial waves such as the selection of wavenumber and period, the selection of vertical wavelength, the coincidence of the vertical structure and so on.

\section{Conclusions and remarks}

A theory for the generation mechanism of stratospheric equatorial waves was proposed. It consists of the following framework.

1) Equatorial waves are formed primarily by a forcing. At this stage, there is already some selectivity determined by the kind and magnitude of the forcing and the response property of waves.

2) These equatorial waves interact with cumulus ensemble. Then, the tropical atmosphere is under the marginally stable state so that only the amplitude of the mode with a particular equivalent depth becomes large sharply.

In item 2), when the Arakawa-Schubert theory is used as the cumulus parameterization scheme, the selected equivalent depth is shorter than the observed one. Therefore, although dominant periods in the stratosphere and the vertical structure in the troposphere of selected waves at the tropopause agree with observations, the vertical wavelength and periods of prominent waves at the tropopause and the vertical structure in the troposphere of selected waves in the stratosphere do not coincide. However, it is essentially dependent on a cumulus parameterization scheme, and a more reasonable parameterization (which will reduce the mass flux of the shallow cloud, therefore the total cloud mass flux) would select a longer equivalent depth. Then, many characteristics observed for equatorial waves may more consistently be explained.

In item 1), if we assume a lateral forcing as the excitation source of mixed Rossby-gravity wave, middle wavenumbers (3-7) are selected as observed and the response amplitude of wavenumbers $1-2$ is considerably small, to the forcing with the large meridional scale, under such equivalent depths as observed. The horizontal structure of the dominant mixed Rossby-gravity wave show the quadrature phase relation of $v^{\prime}$ and $\phi^{\prime}$. Although it is difficult to determine the excitation source of Kelvin wave, if a thermal forcing is assumed to be that at least, the wavenumber 1 is selected as observed.

By paying attention to the structure of this theory that the variation of the amplitude of stratospheric equatorial waves depends on both variations of the magnitude of the forcing and the closeness to the marginal state for the stability of the tropical atmosphere, following investigations will give not only the conclusion for the justice of this theory but also more general suggestions for the generation mechanism of equatorial waves.

1) As the variation of the sea surface temperature (SST) changes the basic state of the tropical atmosphere, observational studies as to what changes are caused for properties of waves from abnormally warm or cold SST, and the comparison between them and predictions from the theory.

2) Theoretical and observational studies for properties of a probable forcing and the excitation of waves by it. For examples, the influence of the horizontal shear to the wavenumber selection for mixed Rossby-gravity wave, and the relationship between the time variation of a forcing and that of the amplitude of equatorial waves.

3) Improvements of the cumulus parameterization. For example, taking the effect of the moist downdraft into the quasi-equilibrium assumption.

\section{Acknowledgements}

The author wishes to express thanks to Prof. R. Yamamoto of Kyoto University for his encouragements and critical reading of the manuscript. Thanks are due to Prof. I. Hirota of Kyoto University for his stimulating discussions and Dr. Y. Hayashi of GFDL, Princeton University, for his many valuable comments.

\section{Appendix}

When we solve Eqs. (20) and (21) regarding the right hand side of Eq. (20) as a forcing term, the solution is as follows (see Eq. (41) in Itoh, 1977):

$$
\begin{aligned}
w= & \left(\lambda_{2}{ }^{2}+\frac{1}{4 H^{2}}\right) \frac{1}{\lambda_{1}^{2}-M^{2}} \\
& \cdot\left[\frac{M}{\lambda_{1} \cos \lambda_{1} z_{t}-i \lambda_{2} \sin \lambda_{1} z} \sin \lambda_{1} z\right.
\end{aligned}
$$




$$
+\sin M z] f w_{b}, \text { for } 0<z<z_{t}, \lambda_{1} \neq M
$$

where $M=\pi / z_{t}$. By substituting values of $w$ and $z$ at the cloud base into (A1), we can obtain the eigen value $h$.

$$
\begin{aligned}
w_{b} & =\left(\lambda_{2}{ }^{2}+\frac{1}{4 H^{2}}\right) \frac{1}{\lambda_{1}^{2}-M^{2}} \\
& \cdot\left[\frac{M}{\lambda_{1} \cos \lambda_{1} z_{t}-i \lambda_{2} \sin \lambda_{1} z_{t}} \sin \lambda_{1} z_{b}\right. \\
& \left.+\sin M z_{b}\right] f w_{b} .
\end{aligned}
$$

As the cloud base is considerably low, $\sin \lambda_{1} z_{b} \sim$ $\lambda_{1} z_{b}$ and $\sin M z_{b} \sim M z_{b}$. Moreover, $\lambda_{1 r} \gg \lambda_{1}{ }^{i}$ and under the marginal state where suffix $\lambda_{2 r} \ll \lambda_{2 i}$ $r$ and $i$ denote real part and imaginary part, respectively. Using these approximations,

$$
\begin{aligned}
& \frac{\lambda_{2 r^{2}}+1 / 4 H^{2}}{\lambda_{1 r^{2}}-M^{2}} M z_{b} \\
& \cdot\left[\frac{2}{e^{i \lambda} r^{z} e-\lambda_{i} z_{t}\left(1-\frac{\lambda_{2}}{\lambda_{1}}\right)+e^{-i \lambda} r^{z}{ }^{z} e^{\lambda_{i}}{ }^{z} t\left(1+\frac{\lambda_{2}}{\lambda_{1}}\right)}\right. \\
& +1\} f \doteqdot 1
\end{aligned}
$$

Since the imaginary part appears only in the term of $e^{i r_{r} z_{t}}$ in the bracket of the left in this equation, $\sin \lambda_{1 r} z_{t}$ must be zero.

$$
\lambda_{1 r} z_{t} \fallingdotseq m \pi \quad(m=1,2 \ldots)
$$

However, $m=1$ is not adequate and, when $m=2$, it becomes unstable to the smallest value of $f$. Setting $m=2$, we obtain

$$
h \doteqdot \frac{\kappa}{H} \frac{z t^{2}}{4 \pi^{2}}\left(\frac{1}{\alpha}-\frac{e}{g}\right) .
$$

On the other hand, as $e=0$ in the CISK parameterization,

$$
h \fallingdotseq \frac{\kappa}{H \alpha} \frac{z t^{2}}{4 \pi^{2}} .
$$

\section{References}

Arakawa, A. and W. Schubert, 1974: Interaction of a cumulus cloud ensemble with the largescale environment. Part I. J. Atmos. Sci., 31, 674-701.

Beland, M., 1976: Numerical study of the nonlinear Rossby wave critical level development in a barotropic zonal flow. J. Atmos. Sci., 33, 2066-2078.

Deland, R. J., 1973: Spectral analysis of traveling planetary scale waves: Vertical structure in middle latitudes of Northern Hemisphere. Tellus,
25, 355-373.

Geisler, J. E. and R. E. Dickinson, 1974: Numerical study of an interacting Rossby wave and barotropic zonal flow near a critical level. J. Atmos. Sci., 31, 946-955.

Gruber, A., 1974: The wavenumber-frequency spectra of satellite-measured brightness in the tropics. J. Atmos. Sci., 31, 1675-1680.

Hayashi, Y., 1970: A theory of large-scale equatorial waves generated by condensation heat and accelerating the zonal wind. J. Meteor. Soc. Japan, 48, 140-160.

—_ 1974: Spectral analysis of tropical disturbances appearing in a GFDL general circulation model. J. Atmos. Sci., 31, 180-218.

-, 1976: Non-singular resonance of equatorial waves under the radiation condition. J. Atmos. Sci., 33, 183-201.

, 1977: Space-time power spectral analysis using the maximum entropy method. J. Meteor. Soc. Japan, 55, 415-420.

Itoh, H., 1977: The response of equatorial waves to thermal forcing. J. Meteor. Soc. Japan, 55, 222239.

Jordan, C. L., 1958: Mean soundings for the west Indies area. J. Meteor., 15, 91-97.

Kousky, V.E. and J. M. Wallace, 1971: On the interaction between Kelvin waves and the mean zonal flow. J. Atmos. Sci., 28, 162-169.

Mak, M. K., 1969: Laterally driven stochastic motions in the tropics. J. Atmos. Sci., 26, 41-64.

Murakami, M., 1974: Influence of mid-latitudinal planetary waves on the tropics under the existence of a critical latitude. J. Meteor. Soc. Japan, 52, 261-271.

Murakami, T., 1972: Equatorial stratospheric waves induced by diabatic heat sources. J. Atmos. Sci., 29, 1129-1137.

Nitta, Tsuyoshi, 1977: Response of cumulus updraft and downdraft to GATE A/B-scale motion system. J. Atmos. Sci., 34, 1163-1186.

Odo, K., 1976: An analysis of stratospheric wave disturbances over the tropical Pacific. J. Meteor. Soc. Japan, 54, 351-360.

Parker, D. E., 1973: Equatorial Kelvin waves at 100 millibars. Quart. J. Roy. Meteor. Soc., 99, 116129.

Stark, T.E., 1976: Wave-CISK and cumulus parameterization. J. Atmos. Sci., 33, 2383-2391.

Tsay, C. Y., 1974: Analysis of large-scale wave disturbances in the tropics simulated by an NCAR global circulation model. J. Atmos. Sci., 31, 330-339.

Wallace, J. M., 1971: Spectral studies of tropospheric wave disturbances in the tropical western Pacific. Rev. Geophys. Space Phys., 9, 557-612.

, and V.E. Kousky, 1968: Observational evidence of Kelvin waves in the tropical stratosphere. J. Atmos. Sci., 25, 900-907. 
Yamazaki, K., 1977: An Arakawa's theory including the effects of critical liquid water in clouds and ice phase. (Unpublished. The May 1977 meetings of the Meteorological Society of Japan.)
Yanai, M. and M. Murakami, 1970: A further study of tropical wave disturbances by the use of spectrum analysis. J. Meteor. Soc. Japan, 48, 186-197.

\title{
Wave-CISK 機構に対して臨界安定状態のもとでの強制赤道波
}

\author{
伊藤 久 徳 \\ 和歌山大学教育学部地学教室
}

成層圏赤道波の励起機構に関する一つの理論を提案した。それは, wave-CISK 機構に対して熱帯大気は臨界安定 状態にあり，赤道波をその状態のもとでの強制波として把えるといら観点である。

その結果, forcing の鉛直形状にかかわらず，臨界状態の波の equivalent depth ないしそれより少し長いそれを 持つモードのみが選択的に励起されることがわかった。積雲の parameterization として Arakawa-Schubert の理 論を用いるとき, 選択される equivalent depth は実測されるものより短かいよらであるが, 少なくとも, 成層圈で 最大振幅を持つ波の周期は実測される周期と一致する。更にいくつかの考察から，より現実的な parameterization のもとでは, より長い equivalent depth が選択されるように思われる。そのときには, 圈界面での卓越周期が成層 圏でのそれに近づき，その波の対流圏での鉛直構造も実測と一致するかもしれない。

この成果のうえにたって, 混合 Rossby 重力波の励起源を lateral forcing と考光, それを (boundary forcing ではなく) 中緯度全体にわたる body forcing として置いたもとで，その波数選択を調べた。大きな南北スケールを 持つ forcing に対しては, 波数 1 や 2 の波は卓越せず，実測されるように中間的な波数 (3〜7) の波が選択される。 また卓越波の水平構造に括いても, 実測される南北風とジオポテンシャルの約 $90^{\circ}$ の位相差を示す。 kelvin 波の励 起源を特定するのは今のところ困難であるが，少なくとも thermal forcing がそれであるとすると，実測される波 数 1 が選択される。

この様にこの理論は成層圈赤道波の説明すべき特徵を良く表わしているように思われる。 